\begin{tabular}{|c|}
\hline Journal of Political Science \\
(A Peer-Reviewed, Open Access International Journal) \\
ISSN 2362-1273 (Print); ISSN 2773-8132 (Online) \\
Volume 21, Feburary 2021, pp. 109-118 \\
https//: www.ejournal of pncampus.edu.np/journals/ips/ \\
\hline
\end{tabular}

\title{
Plagiarism in Scientific Writing: Why It Is Important to Know and Avoid
}

\author{
Min Pun, PhD \\ Department of English \\ Prithvi Narayan Campus, Pokhara
}

Corresponding Author: Min Pun, Email: minpun@pncampus.edu.np

DOI: https://doi.org/10.3126/jps.v21i0.35269

Received 1 December, 2020, Reviewed 15 December 2020, Published 1 February 2021

\begin{abstract}
The main objective of this paper is to discuss plagiarism in relation to research and scientific writing. As the personal computers have become an easy access to the authors, plagiarism is becoming more common while producing any specific scholarly writing. It can range from simple dishonesty to more serious duplications of somebody else's work or idea without giving appropriate credit to the original source. It may sometimes be intentional and sometimes unintentional or direct plagiarism, or self-plagiarism, but plagiarism of any forms or kinds is a serious problem in research and scientific writing. The paper suggests that all researchers, including authors, editors and reviewers should know about the plagiarism and how to avoid it by following ethical guidelines and using the plagiarism detection software. The paper also describes the concept of plagiarism and its various types, providing some important suggestions to avoid it, ensuring research integrity.
\end{abstract}

Keywords: Scientific writing, direct plagiarism, mosaic plagiarism, plagiarism of idea, selfplagiarism, plagiarism detection software

\section{Introduction}

Writing an academic paper requires certain skills. The authors should know how to use others' works or ideas, citing them in a certain academic writing convention. They are required to avoid plagiarism and pay proper attention to citation of references. This is the key requirement necessary to ensure scientific integrity in research and academic publications.

Plagiarism has become a growing concern in the world of academics today, including for colleges and universities. Due to easy availability of the internet and technology, the authors try to find easy ways to accomplish their writing assignments as their "research becomes 


\section{Plagiarism in Scientific Writing}

mere duplication of earlier studies and suffers from lack of originality" (Lakshminarayan \& BK, 2014, p. 3). In the case of university students too, the internet and technology have become easy ways to find solutions to their research problems as they "learn quickly that finding and manipulating data on the Internet is a valuable skill” (Gupta \& Arora, 2015, p. 19). Both types of users do not understand that using someone else's work or idea as if it is their own without acknowledging the original source of information.

Borrowing someone else's work or idea without any credit to the source of origin is plagiarism, which is a term for "stealing, copying others' works" (Masic, 2014, p. 144). In such cases, there can be serious consequences to plagiarism, facing a disciplinary action such as suspension or expulsion from the university, revoking an academic degree, loss of a job and many more according to the context and the severity of plagiarism. In the world of research and academic writing, it has negative consequences such as it may damage the researcher's reputation, lose research funding and be banned from submitting another proposal for a research fund and another manuscript for a journal. As plagiarism is "a serious offense, it is vital that an author makes every effort to avoid committing this act" (Jackowski \& Aaron, 2009, p. 88). In doing so, the researchers and authors can create a unique and authentic academic paper that may result in a successful academic career in the future.

In this paper, the term 'plagiarism' is defined, its types are described and suggestions are given not only to the authors, but also to editors and reviewers to avoid the unethical academic practice. In addition, the paper is written to increase awareness of plagiarism at all levels be it a student, a researcher, an author, or even a university teachers.

\section{What is plagiarism?}

Words and phrases like 'intellectual theft', 'academic dishonesty', 'scientific misconduct', 'cut-copy-paste', 'ethical offense', 'copying', "stealing”, etc. are used to define the terminology 'plagiarism'. In simple words, plagiarism is the use of somebody else's work or idea without acknowledging the original source. American Medical Association (2007) defines it as "the appropriation of another person's ideas, processes, results, or words without giving appropriate credit" (as cited in Jackowski \& Aaron, 2009, p. 88), which is not acceptable in the world of academics and "constitutes misconduct in scientific writing" (Heigeson \& Eriksson, 2014, p. 3). It is rather taken very seriously by academic community, including colleges and universities.

The word 'plagiarism' is derived from the Latin word 'plagiarius' that means 'kidnapper'. Literally, it means that in this action, a person cheats or involves in an illegal action of kidnapping or cheating. The term is now widely used in the world of academics such as in research and in scientific publications. Gibaldi (2004), elaborating on the Latin word meaning, writes about the term saying, "Plagiarism involves two kinds of wrongs. Using another person's ideas, information, or expressions without acknowledging that person's work constitutes intellectual theft. Passing off another person's ideas, information, or expression as your own to get a better grade or gain some other advantage constitutes fraud" (p. 66). Here, in this explanation, two things involve in the act of stealing someone else's work or idea such as plagiarism: an intellectual theft and a fraudulent activity. 


\section{Plagiarism in Scientific Writing}

Although plagiarism is always wrong in the world of academics, it is not clear that whether this act of stealing is legal or ethical. In this case too, Gibaldi (2004) states, "Plagiarism is sometimes a moral and ethical offense rather than a legal one since some instances of plagiarism fall outside the scope of copyright infringement, a legal offense" (66). Whatever the case, plagiarism is taken very seriously by the academic community today and there are many instances of taking legal actions against this practice. Recently, this practice is also considered "a violation of copyright" (Masic, 2014, p. 144). Of course, in many cases, there are many instances of considering this practice as moral or ethical, without taking any disciplinary actions against such practices rather it becomes a matter of public shaming.

There are many reasons of committing plagiarism by the authors. One of the important reasons for this act may be the lack of enough time for writing due to submission deadlines. The second one may be the lack of knowledge about the academic conventions of writing. The authors may not know about what to cite and how to cite the source. The third reason may be poor language skills because the original source needs to be paraphrased, summarized and synthesized in the work skillfully. Language plays a vital role to avoid plagiarism. If the authors are aware of the reasons behind plagiarism, there is less possibility of committing plagiarism in scientific writing.

\section{Forms of Plagiarism}

There are two types of plagiarism. It can be either intentional or unintentional. The first type of plagiarism happens when someone uses someone else's work or idea in partial or in full without giving adequate credit to the original source. The stealing is done deliberately to accomplish the work as if the work is his or her own. In this type of plagiarism, the plagiarist either borrows or copy and paste from other's work without sufficient acknowledgement. Thus, intentional plagiarism is a serious and unethical practice in the academic world.

The second type of plagiarism such as unintentional plagiarism is less serious than the first type of plagiarism. This type of plagiarism happens when the plagiarist has no skills of avoiding plagiarism, but as Jackowski and Aaron (2009) view that "ignorance is not a defense for plagiarism" (p. 88). Usually, inexperienced and young authors commit plagiarism out of "lack of awareness on appropriated referencing and lack of knowledge on what constitutes plagiarism" (Bhushan \& Singh, 2011, p. 150). However, whether it is intentional or unintentional, the plagiarist is not excused by the scientific communities because the plagiarist is copying other's work or idea without proper credit. The only difference between the two is that if the first type is inexcusable, the second type is excusable but still it is wrong to do.

Now, both intentional and unintentional plagiarism can be one of the following forms of plagiarism: direct plagiarism, mosaic plagiarism, paraphrasing or plagiarism of idea, selfplagiarism, and incomplete citation plagiarism. Reciprocally, these forms of plagiarism can also be either intentional or unintentional plagiarism. These forms of plagiarism can be understood clearly with the discussion of them by giving examples. They are discussed below: 


\section{Plagiarism in Scientific Writing}

\section{1) Direct plagiarism (or plagiarism of text, or word-to-word plagiarism):}

This form of plagiarism is easily identifiable because it is directly copied from someone else's work. In the words of Kumar, Priya, Musalaiah, \& Nagasree (2014), it is “just cut and paste from the original source" without appropriate credit (p. 195). It is also called plagiarism of text or word-for-word plagiarism because the whole portion of text is copied from the original source without changing any words. Easy availability of personal computers has made the plagiarists easier to cut and paste materials from one text to another, committing plagiarism in writing. The following is an example of this kind:

\section{Original Version}

"As expected, most of the languages studied are, by most definitions, currently endangered - the type of languages that might feature in UNESCO's Atlas. However, some authors also discuss languages whose vitality (and even dominance in some domains) seems assured in the near future. Their articles are a reminder that language endangerment is a complex and multi-faceted issue, and call for longterm approaches to language preservation."

Cardoso, H.C. (2014). Foreword. In H.C. Cardoso (Ed.), Language endangerment and preservation in South Asia (pp. 1-2). University of Hawai'i Press.

\section{Plagiarized Version}

The past studies made on the language endangerment and preservation in South Asia by various researchers reveal that South Asian countries are diverse in terms of languages, but they also feature prominently in the worldwide charts of linguistic endangerment. The authors included in the book consider language endangerment as a complex and multi-faceted issue and call for long-term approaches to language preservation.

\section{How to Avoid Plagiarism}

The past studies made on the language endangerment and preservation in South Asia by various researchers reveal that South Asian countries are diverse in terms of languages, but they also feature prominently in the worldwide charts of linguistic endangerment. The authors included in the book consider "language endangerment as a complex and multi-faceted issue and call for long-term approaches to language preservation”. (Cardoso 2)

In this example, the author of this text has directly copied the exact words from the original source without acknowledging it. Sometimes, the plagiarist may also copy the whole work or some paragraphs and use in his or her work as the work is his or her own. To avoid plagiarism, it is a good way to put quotation marks within the exact words and cite the source properly.

\section{2) Mosaic plagiarism (or patchwork plagiarism):}

This form of plagiarism is called patchwork plagiarism, which is committed when the authors borrow "ideas and opinions from the original source, a few words and phrase without citing the source” (Masic, 2014, p. 144). It happens when the plagiarist is unable to 


\section{Plagiarism in Scientific Writing}

use his or her own words, he or she uses some of the words from the original source, mixing and making them as his or her own. The product becomes a kind of patchwork, becoming mosaic plagiarism. The following is an example of this kind of plagiarism:

\section{Original Version}

"The quality assurance system employed by Kurdistan Regional Government (KRG) Ministry of Higher Education since 2010, which marked a full implementation in the academic year 2010-2011, makes an interwoven process that involves four programmes: Teaching Quality Assurance (TQA), Continuous Academic Development (CAD), Curriculum Development and Accreditation. Each of these was introduced to monitor the performance of a specific aspect of the higher education system processed by specific procedures and mechanisms designed to suit the education environment in the Region to say the least."

Saeed, S.T. (2018). Impact of quality assurance on academic performance. International Journal of Social Sciences \& Educational Studies, 5(1), pp. 178-190.

\section{Plagiarized Version}

Since 2010, Kurdistan Regional Government Ministry of Higher Education introduced the quality assurance system for the academic year 2010-2011 that included four programmes: Teaching Quality Assurance (TQA), Continuous Academic Development (CAD), Curriculum Development and Accreditation. The main purpose of introducing the system was to implement the internal quality check in the higher education institutions in the region.

\section{How to Avoid Plagiarism}

Since 2010, Kurdistan Regional Government Ministry of Higher Education introduced the quality assurance system for the academic year 2010-2011 that included four programmes: Teaching Quality Assurance (TQA), Continuous Academic Development (CAD), Curriculum Development and Accreditation. The main purpose of introducing the system was to implement the internal quality check in the higher education institutions in the region (Saeed, 2018, p. 179).

In this example, the author has borrowed phrases from the original source without giving credit to the original source. To avoid plagiarism, the author can paraphrase the text and cite the source in a proper way.

\section{3) Paraphrasing plagiarism (or plagiarism of idea):}

Sometimes, paraphrasing can be a form of plagiarism if different words are used to state someone else's idea, presenting it as his or her own, but the person is not given credit for the borrowed idea (Gupta \& Arora, 2015, p. 21). This form of plagiarism is also called plagiarism of idea. An example is given below:

\section{Original Version}

"The caste, class, and gender roles assigned in the Hindu philosophy, which was interdependent in each other, is now diminishing following the demand of society. 


\section{Plagiarism in Scientific Writing}

The living standards of people are increasing and people are taking more facilities as before, for which, everyone seems to be involved in some regular paid work for better remuneration irrespective of the job category.”

Aryal, R.P. (2016). Democratization and development in Nepal. Himalayan Journal of Sociology \& Anthropology, VII, pp. 141-154.

\section{Plagiarized Version}

According to the Hindu philosophy, the roles given by the caste, class and gender system in Nepal does not exist because the society does not entertain the system now. The people have better opportunities than in the past, so they do not have depend on the traditional work distribution.

\section{How to Avoid Plagiarism}

According to the Hindu philosophy, the roles given by the caste, class and gender system in Nepal does not exist because the society does not entertain the system now. The people have better opportunities than in the past, so they do not have depend on the traditional work distribution (Aryal, 2016, p. 152).

In this example, as presented in the plagiarized version, the author has paraphrased the text and used the idea without credit to the original source. This is a wrong way to write scientific paper. It is better to cite the source when the authors paraphrase the text for their writing.

\section{4) Self-plagiarism:}

In this form of plagiarism, the plagiarist steals or borrows some amount of work from his or her own previously published work. This plagiarism is usually committed "to increase the chances of publication or making multiple articles from a single article” (Roka, 2017, p. 4). For instance, if someone uses his or her own work partly and publishes it in another journal that is called self-plagiarism. Here is one example of avoiding this kind of plagiarism:

\section{Original Version}

“Today, the national or regional literature like Nepali writing in English has began to function in the universal canon like the western canon when the international publishers started accepting the works by Nepali writers. In addition, they could easily be documented at length, namely the extent to which the presence of Nepali writers in English on the western markets on who gets published or translated, on what and how well, and on just when. For example, Samrat Upadhyay and Manjushree Thapa are quite well known for the Western readership and well liked because of their books available there."

Pun, M. (2013). Nepali writing in English and the 1990 people's movement in Nepal: Exploring the literary canon. Crosscurrents: A Journal of Language, Literature and Literary Theory, 2(1), pp. 114-131. 


\section{Plagiarism in Scientific Writing}

\section{How to Avoid Plagiarism}

Since Nepali writing in English has begun to function like the western canon, the works of English by Nepali writers have attracted a wider readership (Pun, 2013b, p. 117). For instance, Upadhyay and Thapa are familiar with the academic circles in the west. This is because of their regular presence there. They have also contextualized the question of literary canon in Nepali writing in English.

Pun, M. (2017). The canons of Nepali writing in English. Tribhuvan University Journal, 31(1\&2), pp. 63-74.

In this example, the author has properly cited the borrowed idea from his or her previous work. So it is suggested to cite the source if the original source is from the author's his or her own previous work in order to avoid self-plagiarism.

\section{5) Incomplete citation plagiarism:}

In this form of plagiarism, the reference does not match the original source and sometimes incomplete information is cited from the original source. Sometimes the plagiarist cites the source at the end of every paragraph to avoid plagiarism, but it is wrong. This happens when the plagiarist does not know about what to cite and how to cite the source. The following is one example of this kind:

\section{Example}

Availability of internet facilities and free online journals are the main sources of today's plagiarism among the students, faculty and researchers of any profession. ${ }^{[5,6,14-16]}$

Advancement in technology in conversion of text format into the electronic version, rise in competition levels and "publish or perish" attitude are the some important factors prone to plagiarism among the students/staff/researchers of educational institutions. ${ }^{[15-17]}$

Kumar, P.M., Priya, N.S., Musalaiah, S. \& Nagasree, M. (2014). Knowing and avoiding plagiarism during scientific writing. Annals of Medical and Health Sciences Research, 4(3), 193-198.

In this example, the plagiarist cites the source at the end of each paragraph, which creates confusion because both paragraphs are cited to show the readers that they are not plagiarized. Actually, the author wants to cheat the academic community. There is insufficient acknowledgement in these citations. Such writing creates plagiarism.

\section{Ways to Avoid Plagiarism}

It is important to understand that there are two kinds of information: one is common knowledge information and another is factual information. The first kind of information does not need to be cited because the information found in general sources or references that 


\section{Plagiarism in Scientific Writing}

are known by a lot of people and found in many sources. For instance, the information contained in the sentence 'the earth is round' is common knowledge that does not need to be cited in the work. Similarly, 'Kathmandu is the capital of Nepal' is common knowledge found in many different general sources. So the authors need to identify which information is common knowledge and which is not.

There are other types of information that are not considered common knowledge and always need to be cited in academic writing. If they are not cited, they constitute plagiarism. The factual information is discovered by a specific person such as a researcher and the information becomes the intellectual property of that person. In this case, such information including tables, graphics or pictures should be acknowledged in a proper way so as to avoid plagiarism.

Hundreds and thousands of information are easily available in the physical as well as online library that the authors require them to be included in their work. Ireland and Byrne (2015) view that there are learning technologies that may help students learn about plagiarism (p. 13). At the same time, it is always not easy to add these materials to their work and the work is free of plagiarism. However, there are several ways to avoid plagiarism in the work if certain steps are taken while using someone else's work with confidence and in an ethical way.

- Paraphrase and cite the source: Paraphrasing is one of the simple ways to avoid plagiarism. If the available information is important for the work, it should be read and written with own words, and cite the original source in a proper way.

- Summarize and cite the source: Summarizing is another simple way to avoid plagiarism. The authors need to be efficient enough to summarize the available information and cite the original source properly.

- Quote and cite the source: When the authors think that a portion of the exact text should be presented in their work as it is, which creates effectiveness in their work, the exact lines should be copied in the work and cited the original source properly. The copied text should either be put within the double quotation marks or indented as per the academic style prescribed by the journal or research funding institution.

- Cite own materials: If the authors use their own previous work in their writing, they should cite it. It becomes self-plagiarism if the information is borrowed from the own previous work.

- Always follow the rules: This is probably the most important tip to avoid plagiarism. If the authors always follow the certain convention of writing, plagiarism can be avoided. There are many such formatting styles (rules of writing) that are prescribed by the journals and research funding institutions. They include MLA, APA, Chicago, Vancouver and many others. These formatting styles guide the authors to properly cite the references and give credit to the original sources.

- Use plagiarism detection software: In today's world, the modern technology has made all to use and reuse online materials easily, but the same technology can be used to develop software for the detection of academic plagiarism. There are several free and open-source plagiarism detection tools available online. There are also 


\section{Plagiarism in Scientific Writing}

payable tools available to detect plagiarism in academic submissions. The payable plagiarism detection software are more reliable than the software available free of cost online. It is the authors, editors and reviewers' responsibility to avoid plagiarism. In this process of avoiding academic dishonesty, they should use plagiarism detection software. However, it is suggested that the software should be authentic and mostly it depends on "human analysis" for accurate results (Masic, 2014, p. 145). But still, whether it is free of cost or payable software, there is no guarantee of detecting plagiarism in scientific papers as many editors continue to find plagiarized works even after the journals get published.

\section{Conclusion}

Plagiarism is more common in the world of academics, including colleges and universities. Due to easy access to personal computers, the authors commit plagiarism intentionally and sometimes unintentionally to reduce their workload and find easy ways to accomplish their projects. Plagiarism can be direct, mosaic, self, paraphrase and incomplete citation. It may have serious consequences, ranging from disciplinary action to suspension or expulsion from the institution, and loss of a job to blacklisting for future submissions. So it is necessary for the authors, editors, and reviewers to know about plagiarism and how to avoid it in research and academic publications.

It is suggested that the authors should follow ethical guidelines and use the plagiarism detection software while writing scientific papers and maintaining research integrity. For instance, the authors should properly cite the sources of information, providing the original sources' information. In many cases, plagiarism happens when the authors are unaware of the basic rules of academic writing. So the negative consequences of plagiarism can be reduced when the authors are given proper instructions by the funding institutions and publishing institutions.

\section{References}

Aryal, R.P. (2016). Democratization and development in Nepal. Himalayan Journal of Sociology \& Anthropology, VII, 141-154.

Cardoso, H.C. (2014). Foreword. In H.C. Cardoso (Ed.), Language endangerment and preservation in South Asia (pp. 1-2). University of Hawai'i Press.

Gibaldi, J. (2004). MLA handbook for writers of research papers ( $6^{\text {th }}$ ed.). Affiliated EastWest Press.

Gupta, N. \& Arora, V. (2015). Plagiarism: An academic dishonesty! Journal of Updates in Dentistry, 4(1), 19-23.

Heigesson, G. \& Eriksson, S. (July 2014). Plagiarism in research. Medicine Health Care and Philosophy, 18(1), 91-101. https://www.researchgate.net/publication/263743965 


\section{Plagiarism in Scientific Writing}

Ireland, C. \& Byrne, G. (2015). Using technology to prevent plagiarism: skilling the students. Working paper. University of Huddersfield, Huddersfield. http://eprints.hud.ac.uk/id/eprint/12132/.

Jackowski, M. \& Aaron, L. (2009). If you use it, cite it. Radiologic Technology, 81(1), pp. 88-89. https://www.researchgate.net/publication/26797035.

Kumar, P.M., Priya, N.S., Musalaiah, S. \& Nagasree, M. (2014). Knowing and avoiding plagiarism during scientific writing. Annals of Medical and Health Sciences Research, 4(3), 193-198.

Lakshminarayan, N. \& BK, S. (2014). Assessment of the attitude towards plagiarism among dental postgraduate students and faculty members in Bapuji Dental College and Hospital, Davangere - A cross sectional survey. IOSR Journal of Dental and medical Sciences, 13(5/IV), 1-6.

Masic, I. (2014). Plagiarism in scientific research and publications and how to prevent it. Mater Sociomed, 26(2), 141-146.

Pun, M. (2013). Nepali writing in English and the 1990 people's movement in Nepal: Exploring the literary canon. Crosscurrents: A Journal of Language, Literature and Literary Theory, 2(1), 114-131.

Pun, M. (2017). The canons of Nepali writing in English. Tribhuvan University Journal, 31(1\&2), 63-74.

Roka, Y.B. (2017). Plagiarism: Types, causes and how to avoid this worldwide problem. Nepal Journal of Neuroscience, 14(3), 2-6.

Saeed, S.T. (2018). Impact of quality assurance on academic performance. International Journal of Social Sciences \& Educational Studies, 5(1), 178-190.

Sharma, B.B. \& Singh, V. (2014). Ethics in writing: Learning to stay away from plagiarism and scientific misconduct. Lung India, 28(20/2), 148-150. 